\title{
PARAMETRIC STUDY OF MULTI-SPOT WELDED LAP SHEAR SPECIMEN FOR TENSILE AND SHEAR STRENGTH
}

\author{
Kisanlal B. Badole (Scholar) \\ Department of Mechanical Engineering \\ K.D.K. College of Engineering, \\ Nagpur, Maharashtra, India
}

\author{
Dr. P. G. Mehar (Assistant Professor) \\ Department of Mechanical Engineering \\ K.D.K. College of Engineering, \\ Nagpur, Maharashtra, India
}

\begin{abstract}
The effect of number of spots, spot spacing, squeezing force, welding current, weld time, overlapping length and sheet thickness on the tensile and shear strength of two similar galvanized steel sheets are investigated through experiments using RSM method and by using software. Similar sheets of galvanized steel sheets are made by resistance spot welding at different processing conditions and these joint populations were tested under lap-shear loading conditions. Specially fabricated fixture is used to load the lap shear specimen in the universal testing machine Regression analysis is done to obtain relationship between shear strength and selected parameters. The experimental results indicate that the failure loads of spot welds in lap-shear specimens increase when number of spot, squeezing force, welding current and sheet thickness increase for the given ranges.
\end{abstract}

Keywords- Number of spots, Shear Strength, Process parameters

\section{INTRODUCTION}

Resistance spot welding (RSW) is a process of joining metal components through the fusion of discrete spots at the interface of the work pieces. It is one of the most useful and practical methods for the manufacture of sheet metal assemblies. This process is common for welding sheets of aluminium, stainless steel, titanium alloys etc. A typical automobile consists of more than 5000 spots This study gives relationship among process parameters and strength of spot weld. Galvanized sheets are spot welded at permissible level of parameters so as to visualize interfacial mode of failure after tensile shear test Author considered processing time as parameter. It was observed that shear strength of spot weld increases with increasing processing time This study consists of application of Taguchi method to study effect of process parameters on strength of spot weld This study consists of relationship between pre- straining and shear strength of spot weld Lap shear specimen is used and its fatigue strength is obtained through experimentation.

Effect of nugget diameter on fatigue strength of spot weld is studied. Effect of fusion zone size on the shear strength is studied. Experiments were planned on the basis of response surface methodology (RSM) and by using software.
Strength of spot weld defines the quality of integrated structure of automobile and improves the reliability of assembled sheets. Structural stability of multi spot welded structure depends upon number of spots, their locations and variable loads acting on it. So, investigation on the relations between the strength of spot weld and number of spots is the key to solve problem in the design of multi-spot welded structure. The diameter of the spot weld nugget, d, ischosen based on an empirical formula recommended by the American Welding Society (AWS), diameter of nugget is considered as follows.

$$
\mathrm{d} \geq 4 \overline{\mathrm{t}}
$$

However, several author claim that this equation is not safe for thickness beyond $1.5 \mathrm{~mm}$. Though the effect of the process parameters on the mechanical behaviour of resistance spot welds on steels is well documented, study of failure modes of spot weld.

Table I .Chemical Composition of Galvanized steel sheet

\begin{tabular}{|c|c|c|c|c|c|c|c|}
\hline T.S & Y.S & \multirow{2}{*}{\multicolumn{6}{|c|}{ Alloying elements (wt \%) }} \\
\hline \multicolumn{2}{|c|}{ MPa } & & & & & & \\
\hline \multirow{2}{*}{350} & \multirow{2}{*}{240} & $\mathrm{c}$ & $\mathrm{Mn}$ & $\mathrm{Si}$ & $\mathrm{S}$ & $p$ & $\mathrm{Cr}$ \\
\hline & & 0.16 & 0.30 & 0.25 & 0.030 & 0.03 & 0.004 \\
\hline
\end{tabular}

The welds were done using a RSW electric resistance spot welding machine, with a nominal welding power of $10 \mathrm{kVA}$. Table II shows ranges of parameters and table III shows Resistance spot welding parameters and corresponding strength.

\section{EXPERIMENTAL PROCEDURE}

Mechanical properties of galvanized steels are given in Table 1. Resistance spot welding lap joints were done on specimens of $120 \mathrm{~mm} \times 200 \mathrm{~mm} \times 1.22 \mathrm{~mm}$ in size. Figure1 shows the geometry and dimensions of the welded specimens. Sheet surfaces were randomly abraded with silicon carbide paper P220 grade. Figure 2 shows local display of experimental set up 


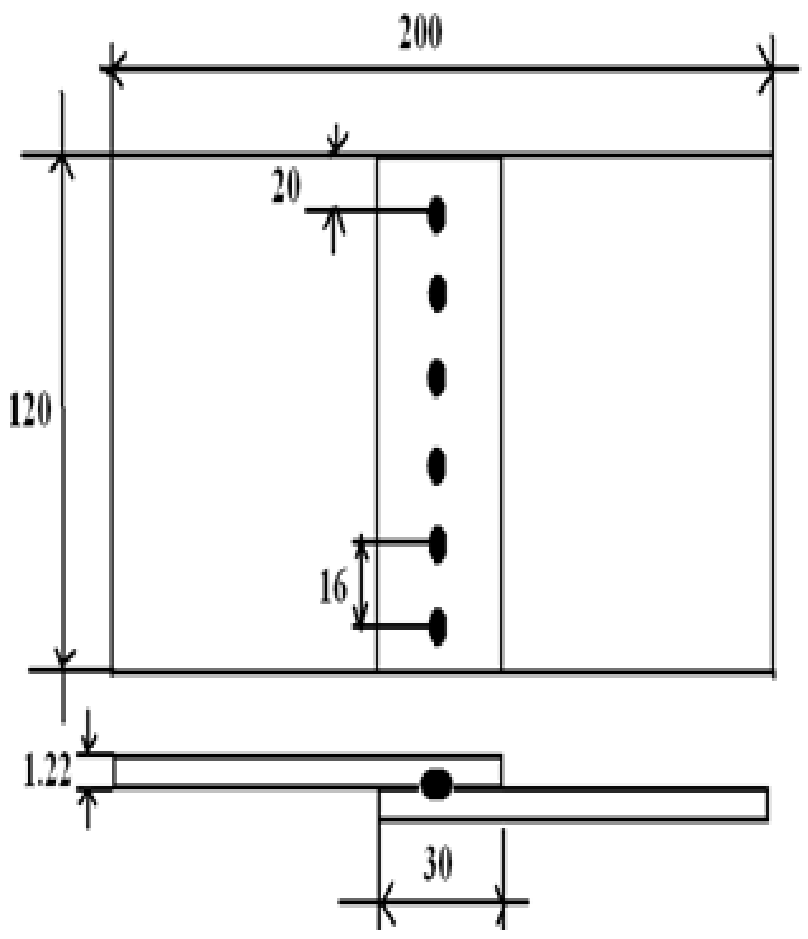

Fig.1. Dimensions of tensile-shear test specimens (not to scale, dimensions in $\mathrm{mm}$ ).

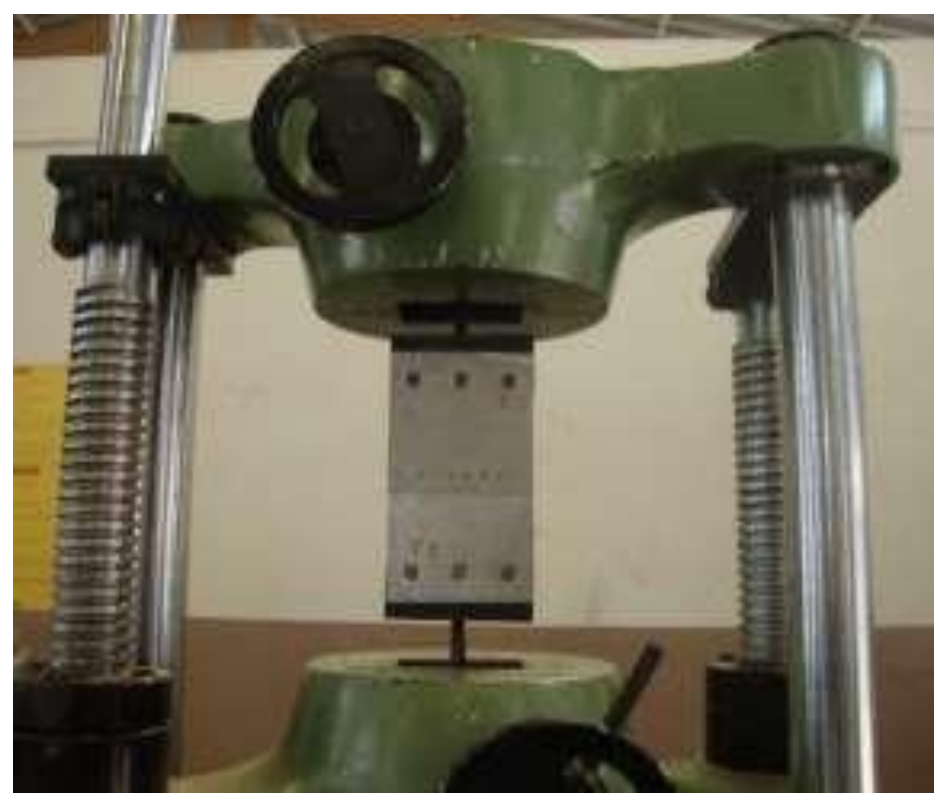

Fig.2 Local display of experimental set up

Table II: Ranges of parameters

\begin{tabular}{|l|l|l|l|l|}
\hline Sr. & Parameters & \multicolumn{3}{|l|}{ Level } \\
\cline { 3 - 5 } No & and Designations & Low & Medium & High \\
\hline 1 & Force (F) & 2000 & 2500 & 3000 \\
\hline & & & & \\
\hline 2 & Number of spots(n) & 2 & 4 & 6 \\
\hline 3 & spot spacing (X) & 12 & 14 & 16 \\
\hline 4 & Thickness(t) & 1.2 & 1.5 & 1.8 \\
\hline 5 & Current(I) & 8000 & 85000 & 9000 \\
\hline 6 & $\begin{array}{l}\text { Welding } \\
\text { (Cycles) }\end{array}$ & 5 & 7 & 8 \\
\hline 7 & Overlapping length & 33 & 38 & 43 \\
\hline
\end{tabular}

Table III. Resistance spot welding parameters and corresponding strength (Response Surface Methodology)

\begin{tabular}{|c|c|c|c|c|c|c|c|c|}
\hline Sr.No & $\mathbf{F}(\mathbf{N})$ & $\mathbf{I}(\mathbf{A m p})$ & $\mathbf{T}(\mathbf{m m})$ & $\mathbf{t}(\mathbf{c y c l e s})$ & $\mathbf{R}(\mathbf{m m})$ & $\mathbf{n}$ & $\mathbf{O L}(\mathbf{m m})$ & $\mathbf{T . S}(\mathbf{N})$ \\
\hline 1 & 2500 & 8000 & 1.5 & 7 & 14 & 4 & 38 & 6598.52 \\
\hline 2 & 3000 & 9000 & 1.2 & 5 & 16 & 2 & 33 & 8079.62 \\
\hline 3 & 2000 & 8000 & 1.8 & 5 & 16 & 6 & 33 & 6500.95 \\
\hline 4 & 2000 & 9000 & 1.2 & 5 & 16 & 2 & 43 & 8055.32 \\
\hline 5 & 3000 & 9000 & 1.8 & 5 & 16 & 2 & 43 & 8180.85 \\
\hline 6 & 2500 & 8500 & 1.5 & 7 & 9 & 4 & 38 & 7318.22 \\
\hline 7 & 3000 & 9000 & 1.2 & 8 & 16 & 6 & 33 & 8091.42 \\
\hline 8 & 2000 & 9000 & 1.8 & 8 & 16 & 6 & 33 & 7970.95 \\
\hline 9 & 2500 & 8500 & 1.5 & 7 & 14 & 4 & 38 & 7333.52 \\
\hline 10 & 2000 & 8000 & 1.2 & 5 & 16 & 6 & 43 & 6597.12 \\
\hline 11 & 2000 & 9000 & 1.8 & 5 & 12 & 2 & 43 & 8045.61 \\
\hline
\end{tabular}


International Journal of Engineering Applied Sciences and Technology, 2021

Vol. 6, Issue 1, ISSN No. 2455-2143, Pages 430-436

Published Online May 2021 in IJEAST (http://www.ijeast.com)

\begin{tabular}{|c|c|c|c|c|c|c|c|c|}
\hline 12 & 3000 & 8000 & 1.2 & 5 & 12 & 2 & 33 & 6597.38 \\
\hline 13 & 3000 & 9000 & 1.8 & 5 & 12 & 2 & 33 & 8069.91 \\
\hline 14 & 2500 & 9914.21 & 1.5 & 7 & 14 & 4 & 38 & 9412.41 \\
\hline 15 & 3000 & 9000 & 1.2 & 5 & 16 & 6 & 43 & 8190.12 \\
\hline 16 & 3000 & 8000 & 1.8 & 5 & 12 & 2 & 43 & 6698.61 \\
\hline 17 & 2500 & 8500 & 1.5 & 7 & 14 & 4 & 38 & 7333.52 \\
\hline 18 & 3000 & 8000 & 1.2 & 8 & 12 & 6 & 33 & 6609.18 \\
\hline 19 & 2000 & 9000 & 1.2 & 5 & 12 & 2 & 33 & 7944.38 \\
\hline 20 & 2500 & 8500 & 0.6 & 7 & 14 & 4 & 38 & 7329.73 \\
\hline 21 & 3000 & 9000 & 1.2 & 5 & 12 & 2 & 43 & 8166.08 \\
\hline 22 & 3000 & 9000 & 1.8 & 8 & 16 & 2 & 33 & 8082.15 \\
\hline 23 & 3000 & 8000 & 1.2 & 8 & 16 & 6 & 43 & 6720.12 \\
\hline 24 & 2000 & 9000 & 1.8 & 5 & 16 & 2 & 33 & 7959.15 \\
\hline 25 & 2000 & 8000 & 1.8 & 5 & 16 & 2 & 43 & 6587.85 \\
\hline 26 & 2500 & 8500 & 1.5 & 7 & 14 & 4 & 52 & 7471.7 \\
\hline 27 & 2500 & 8500 & 1.5 & 7 & 14 & 4 & 38 & 7333.52 \\
\hline 28 & 3000 & 9000 & 1.8 & 8 & 12 & 6 & 33 & 8081.71 \\
\hline 29 & 2000 & 9000 & 1.2 & 8 & 12 & 2 & 43 & 8043.08 \\
\hline 30 & 2000 & 8000 & 1.2 & 8 & 16 & 6 & 33 & 6498.42 \\
\hline 31 & 3000 & 8000 & 1.8 & 8 & 16 & 2 & 43 & 6710.85 \\
\hline 32 & 2500 & 8500 & 1.5 & 7 & 14 & 4 & 38 & 7333.52 \\
\hline 33 & 2000 & 8000 & 1.8 & 8 & 12 & 2 & 43 & 6575.61 \\
\hline 34 & 2500 & 8500 & 1.5 & 7 & 14 & 4 & 23 & 7185.47 \\
\hline 35 & 2500 & 8500 & 1.5 & 7 & 14 & -2 & 38 & 7315.82 \\
\hline 36 & 2500 & 8500 & 1.5 & 7 & 14 & 6 & 38 & 7339.42 \\
\hline 37 & 2000 & 8000 & 1.8 & 8 & 12 & 6 & 33 & 6488.71 \\
\hline 38 & 2000 & 9000 & 1.2 & 8 & 16 & 6 & 43 & 8067.12 \\
\hline 39 & 2000 & 9000 & 1.2 & 8 & 12 & 6 & 33 & 7956.18 \\
\hline 40 & 2000 & 9000 & 1.8 & 5 & 12 & 6 & 33 & 7958.71 \\
\hline 41 & 2000 & 8000 & 1.2 & 5 & 12 & 6 & 33 & 6486.18 \\
\hline 42 & 2500 & 8500 & 1.8 & 7 & 14 & 4 & 38 & 7334.78 \\
\hline 43 & 2000 & 8000 & 1.2 & 8 & 12 & 6 & 43 & 6584.88 \\
\hline 44 & 3000 & 9000 & 1.8 & 8 & 16 & 6 & 43 & 8192.65 \\
\hline 45 & 2500 & 8500 & 1.5 & 7 & 14 & 4 & 38 & 7333.52 \\
\hline 46 & 2000 & 8000 & 1.2 & 8 & 16 & 2 & 43 & 6585.32 \\
\hline 47 & 2000 & 9000 & 1.8 & 8 & 12 & 2 & 33 & 7946.91 \\
\hline 48 & 2000 & 8000 & 1.2 & 5 & 12 & 2 & 43 & 6573.08 \\
\hline 49 & 2000 & 8000 & 1.8 & 5 & 12 & 2 & 33 & 6476.91 \\
\hline 50 & 2500 & 8500 & 1.5 & 11 & 14 & 4 & 38 & 7333.52 \\
\hline 51 & 2500 & 8500 & 1.5 & 3 & 14 & 4 & 38 & 7333.52 \\
\hline 52 & 3000 & 8000 & 1.2 & 5 & 12 & 6 & 43 & 6707.88 \\
\hline 53 & 3000 & 9000 & 1.2 & 8 & 12 & 2 & 33 & 8067.38 \\
\hline 54 & 2500 & 8500 & 1.5 & 7 & 14 & 4 & 38 & 7333.52 \\
\hline
\end{tabular}


International Journal of Engineering Applied Sciences and Technology, 2021 Vol. 6, Issue 1, ISSN No. 2455-2143, Pages 430-436

Published Online May 2021 in IJEAST (http://www.ijeast.com)

\begin{tabular}{|c|c|c|c|c|c|c|c|c|}
\hline 55 & 2500 & 8500 & 1.5 & 7 & 14 & 4 & 38 & 7333.52 \\
\hline 56 & 2000 & 9000 & 1.2 & 8 & 16 & 2 & 33 & 7956.62 \\
\hline 57 & 2000 & 9000 & 1.8 & 8 & 16 & 2 & 43 & 8057.85 \\
\hline 58 & 2000 & 9000 & 1.8 & 5 & 16 & 6 & 43 & 8069.65 \\
\hline 59 & 2000 & 9000 & 1.2 & 5 & 12 & 6 & 43 & 8054.88 \\
\hline 60 & 3000 & 9000 & 1.2 & 8 & 16 & 2 & 43 & 8178.32 \\
\hline 61 & 3000 & 9000 & 1.8 & 5 & 16 & 6 & 33 & 8093.95 \\
\hline 62 & 3000 & 9000 & 1.8 & 8 & 12 & 2 & 43 & 8168.61 \\
\hline 63 & 2500 & 8500 & 1.5 & 7 & 14 & 4 & 38 & 7333.52 \\
\hline 64 & 2000 & 8000 & 1.8 & 8 & 16 & 6 & 43 & 6599.65 \\
\hline 65 & 4000 & 8500 & 1.5 & 7 & 14 & 4 & 38 & 7518.02 \\
\hline 66 & 3000 & 8000 & 1.8 & 5 & 12 & 6 & 33 & 6611.71 \\
\hline 67 & 2000 & 8000 & 1.8 & 8 & 16 & 2 & 33 & 6489.15 \\
\hline 68 & 3000 & 8000 & 1.2 & 5 & 16 & 2 & 43 & 6708.32 \\
\hline 69 & 3000 & 9000 & 1.2 & 8 & 12 & 6 & 43 & 8177.88 \\
\hline 70 & 3000 & 8000 & 1.8 & 5 & 16 & 2 & 33 & 6612.15 \\
\hline 71 & 2000 & 8000 & 1.8 & 5 & 12 & 6 & 43 & 6587.41 \\
\hline 72 & 3000 & 8000 & 1.2 & 8 & 16 & 2 & 33 & 6609.62 \\
\hline 73 & 3000 & 9000 & 1.8 & 5 & 12 & 6 & 43 & 8180.41 \\
\hline 74 & 2000 & 8500 & 1.5 & 7 & 14 & 4 & 38 & 7272.02 \\
\hline 75 & 2000 & 9000 & 1.8 & 8 & 12 & 6 & 43 & 8057.41 \\
\hline 76 & 3000 & 8000 & 1.8 & 8 & 16 & 6 & 33 & 6623.95 \\
\hline 77 & 3000 & 9000 & 1.2 & 5 & 12 & 6 & 33 & 8079.18 \\
\hline 78 & 3000 & 8000 & 1.2 & 8 & 12 & 2 & 43 & 6696.08 \\
\hline 79 & 2500 & 8500 & 1.5 & 7 & 19 & 4 & 38 & 7348.82 \\
\hline 80 & 3000 & 8000 & 1.8 & 5 & 16 & 6 & 43 & 6722.65 \\
\hline 81 & 2500 & 8500 & 1.5 & 7 & 14 & 4 & 38 & 7333.52 \\
\hline 82 & 3000 & 8000 & 1.8 & 8 & 12 & 6 & 43 & 6710.41 \\
\hline 83 & 2000 & 8000 & 1.2 & 8 & 12 & 2 & 33 & 6474.38 \\
\hline 84 & 3000 & 8000 & 1.8 & 8 & 12 & 2 & 33 & 6599.91 \\
\hline 85 & 2000 & 9000 & 1.2 & 5 & 16 & 6 & 33 & 7968.42 \\
\hline 86 & 2500 & 8500 & 1.5 & 7 & 14 & 4 & 38 & 7333.52 \\
\hline 87 & 2000 & 8000 & 1.2 & 5 & 16 & 2 & 33 & 6486.62 \\
\hline 88 & 3000 & 8000 & 1.2 & 5 & 16 & 6 & 33 & 6621.42 \\
\hline
\end{tabular}




\section{International Journal of Engineering Applied Sciences and Technology, 2021 \\ Vol. 6, Issue 1, ISSN No. 2455-2143, Pages 430-436 \\ Published Online May 2021 in IJEAST (http://www.ijeast.com)}

The shear strength testing was done in a servo hydraulic Universal Testing machine at a constant cross-head speed of $1.31 \mathrm{~mm} / \mathrm{min}$ up to the final failure of the joint. Specimen failed Partially by pull out faiure mode under constant loading velocity. Eqaution 2 is regression equation

$$
\begin{aligned}
\mathrm{P}= & -5905+0.123 \times \mathrm{f}+1.47 \times \mathrm{I}+4.21 \times \mathrm{T}+0.000242 \times \mathrm{t} \\
& +3.06 \times \mathrm{X}+2.94 \times \mathrm{n}+9.86 \times \mathrm{OL}
\end{aligned}
$$

Where,

$\mathrm{P}=$ Shear Strength $(\mathrm{N})$.

$\mathrm{f}=$ Electrode force $(\mathrm{N}) \mathrm{I}=$ Current

(Amp) $\mathrm{T}=$ Thickness in $\mathrm{mm}$

$\mathrm{t}=$ Weld time (Cycle)

$\mathrm{X}=$ Spot spacing $(\mathrm{mm})$

$\mathrm{n}=$ Number of spots

$\mathrm{OL}=$ Overlapping Length. $(\mathrm{mm})$

\section{RESULT AND DISCUSSION}

According to the results of experimentations and regression analysis, effect of number of spot, distance between two spot, electrode force, weld current and specimen thickness is obtained. Scattered plots are drawn according to the design matrix RSMAll spots are failed at once due to axially applied load and it is uniformly distributed over sheet surface.

Weld time:-Current and electrode force are kept constant while weld time is varied within a range 3 to 7 cycles. It is observed that there is large increase strength after 5 cycles of welding .welds obtained between times 6 and 7 cycles are failed in nugget pullout failure mode as shown in Fig.3. Spot welds made at time range 3 5 cycles fail in interfacial failure mode.

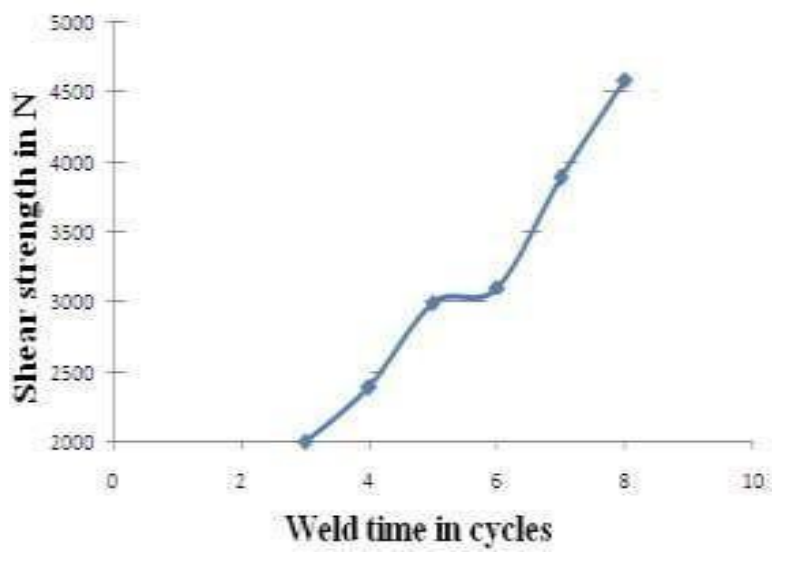

Fig.3 Relationship between weld time and shear strength
Electrode force:-It is observed that there is large increase in strength after 5 cycles of welding .welds obtained between times 6 and 7 cycles are failed in nugget pullout failure mode as shown in Fig 4. Spot welds made at time range $3-5$ cycles fail in interfacial failure mode.

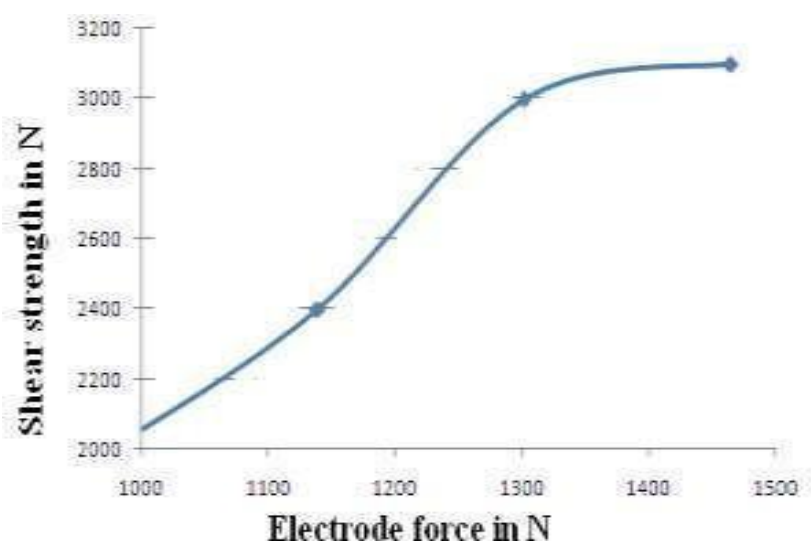

Fig.4 Electrode force Vs shear strength

It is observed that spot welds made at electrode force $5464.66 \mathrm{~N}$ fail in pull out failure mode and remaining welds fail in interfacial failure mode.

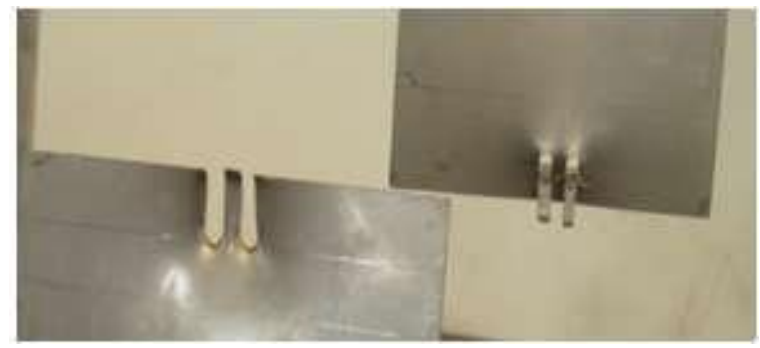

Fig.5 .Pull out failure mode

A considerable bending of specimen is observed when component fails in pull out failure mode. Pull out failure of specimen is observed only at higher level of process parameters.

Number of spots: - All spots are failed at once due to axially applied load and it is uniformly distributed over sheet surface. 


\section{International Journal of Engineering Applied Sciences and Technology, 2021 \\ Vol. 6, Issue 1, ISSN No. 2455-2143, Pages 430-436 \\ Published Online May 2021 in IJEAST (http://www.ijeast.com)}

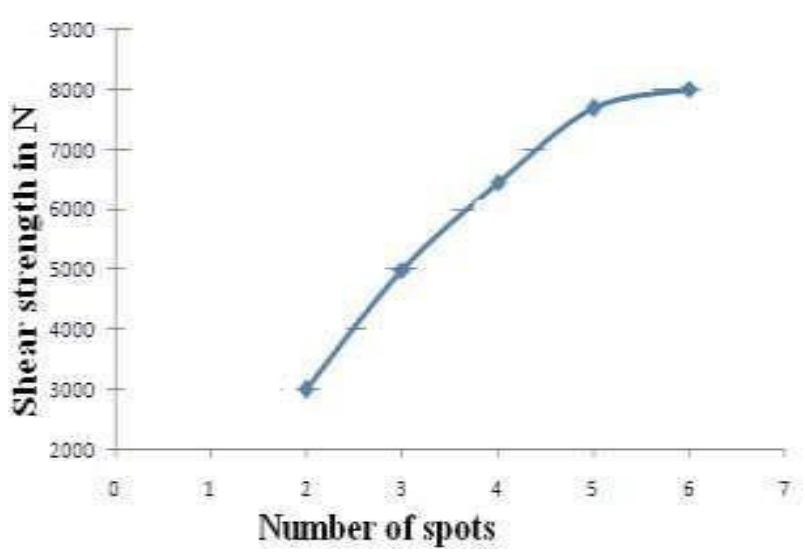

\section{Fig.6 Relationship Between Number Of Spots AND SHEAR STRENGTH}

It is observed that there is significant increase in shear strength of spot weld when number of spot increase. Fig.6 shows relationship between number of spot and tensile shear strength of spot weld. Specimens having six number of spot but made at lower values of other parameters, got the strength 5002.63N.Spot welds made at lower level are failed in interfacial failure mode while spot welds made at higher level are failed at pullout failure mode. All spots were failed at once due to axially applied load and it is uniformly distributed over sheet surface.

Spot welding current:-It is observed that there is significant increase in shear strength of spot weld when spot welding current increases. Fig.7 shows relationship between spot welding current and shear strength of spot weld. Spot welds made at 9 Kamp current and having six number of spots, got the strength $7689.906 \mathrm{~N}$.Spot welds made at 9 Kamp current but having lower value of thickness and number of spot, got the strength $3073.97 \mathrm{~N}$.

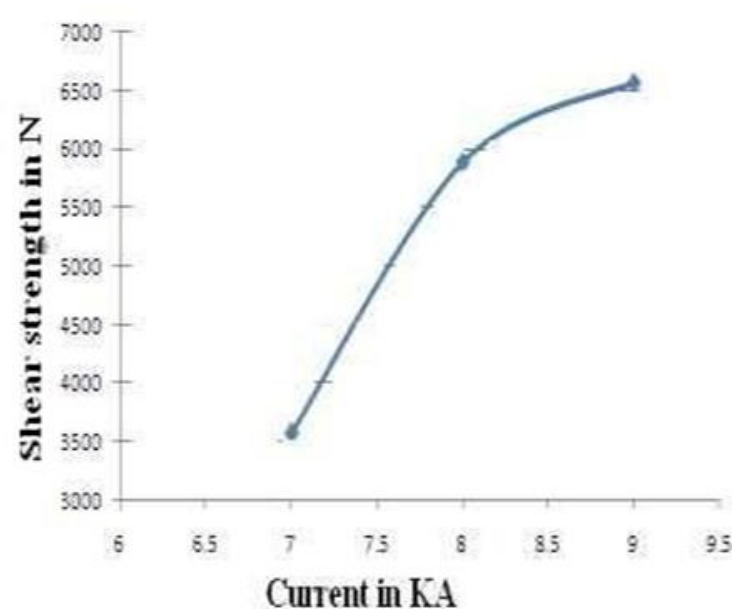

Fig 7 Relationship between current and shear strength

Work piece thickness:-It is observed that there is significant increase in shear strength of spot weld when specimen thickness increases.

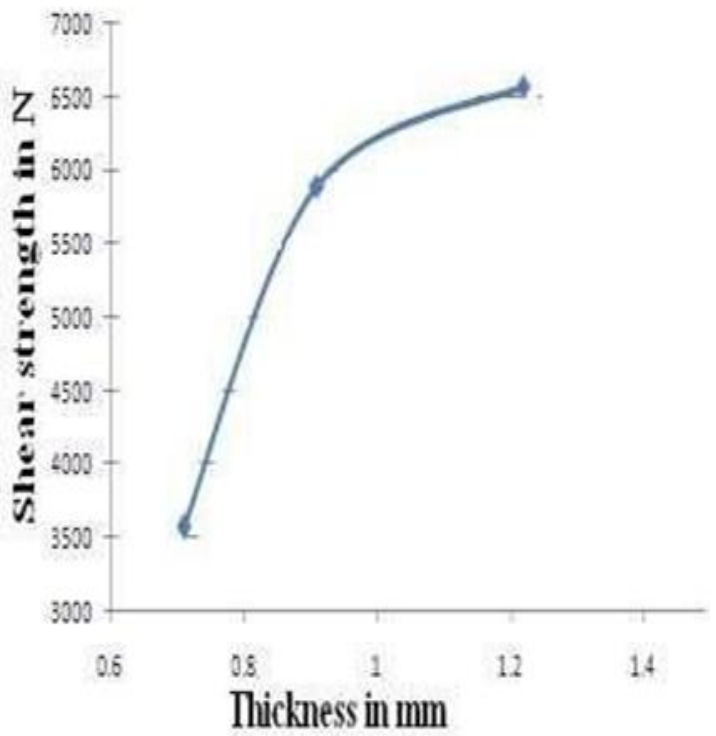

Fig 8 Relationship between specimen thickness and shear strength

Fig. 8 shows relationship between Specimen thickness and shear strength of spot weld. Spot welds made $1.22 \mathrm{~mm}$ thickness and having six numbers of spots, got the strength $7589.99 \mathrm{~N}$. It is observed that compromising with number of spots and increasing specimen thickness shear strength can be improved. Spot welds made $1.22 \mathrm{~mm}$ thickness but having lower value of current and number of spot, got the strength $3507.99 \mathrm{~N}$.

Spot spacing:-It is observed that there is significant increase in shear strength of spot weld when distance between two spot decreases in between range $10 \mathrm{~mm}-13 \mathrm{~mm}$.

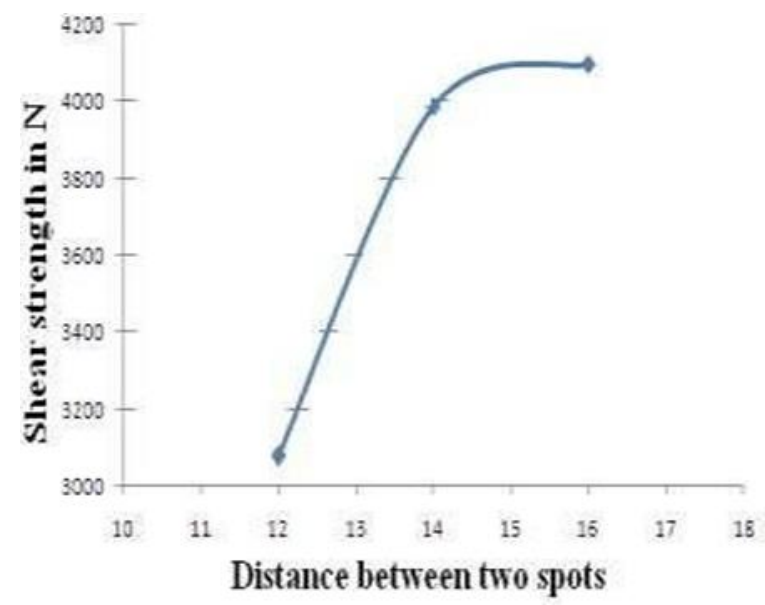

Fig 9 Relationship between distance between spots and shear strength of spot weld

This is the least range at which there was no overlapping of two spots. Fig.9 shows relationship between distance between two spot and shear strength of spot weld. Spot welds 


\section{International Journal of Engineering Applied Sciences and Technology, 2021 \\ Vol. 6, Issue 1, ISSN No. 2455-2143, Pages 430-436 \\ Published Online May 2021 in IJEAST (http://www.ijeast.com)}

made at distance $16 \mathrm{~mm}$ and having six numbers of spots, got the strength in between the range $8531.97 \mathrm{~N}$.

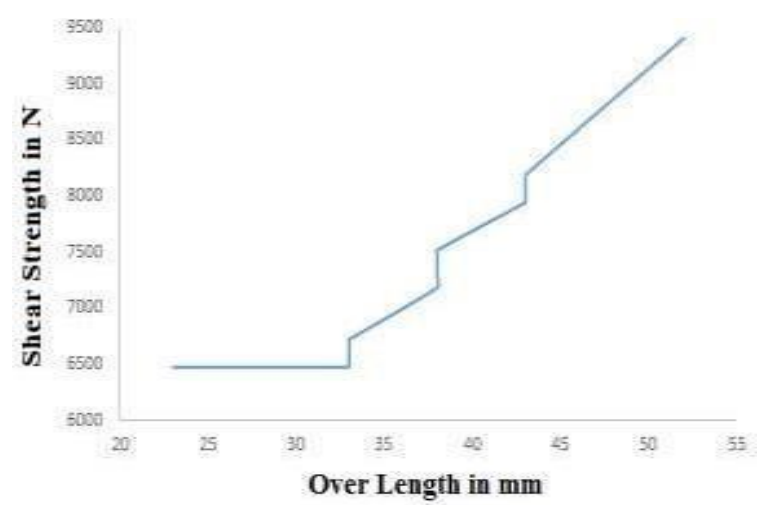

Fig 10 Relationship between Over lapping length and shear strength of spot weld

It is observed that up to certain range of distance between two spots, shear strength increases and after that strength decreases. Spot welds made $1.22 \mathrm{~mm}$ thickness but having lower value of current and number of spot, got the strength 3776.97N. Tensile shear strength starts decreasing when distance between two spot is more than $18 \mathrm{~mm}$ for six numbers of spots.

It is observed that there is significant increase in shear strength of spot weld when specimen over length increases. Fig.10 shows relationship between Specimen over length and shear strength of spot weld. Spot welds made $45 \mathrm{~mm}$ over lapping length and having six numbers of spots, got the strength $7589.99 \mathrm{~N}$. It is observed that compromising with spot spacing and increasing specimen thickness shear strength can be improved. Spot welds made $20 \mathrm{~mm}$.over lapping length but having lower value of current and number of spot, got the strength $6507.99 \mathrm{~N}$.

Table IV Result of Confirmation test $(P$ in $N)$

\begin{tabular}{|l|l|l|}
\hline Sr.No & Regression model & Experimental \\
\hline 1 & 4801.1 & 4806.78 \\
\hline 2 & 3330.1 & 3319.13 \\
\hline 3 & 5621.87 & 5591.91 \\
\hline 4 & 6241.13 & 6211.83 \\
\hline 5 & 5182.92 & 5153.12 \\
\hline
\end{tabular}

\section{CONCLUSION}

The conclusions obtained are summarised as follow

1 The response surface methodology is used to evaluate the effects of selected spot welding process and design parameters. It is an effective method used in the experimental design and the investigation for regression models between spot welding process and RSW quality of galvanized steel sheet.

2 The effect of selected welding process parameters and design parameters on the tensile- shear strength can be analysed on the basis of mathematical regression models of galvanized steel sheet and it can provide profitable reference to welding process devising as an assistant means.

3 The effect of number of spots on the shear strength of spot weld is analysed. There is significant increase in the strength of spot weld as strength increases. Moreover, effects of distance between two spot and over lapping length on the strength of spot weld have been analysed. This study helps to find optimum number of spots, over lapping length and optimum distance between two spot.

\section{REFERENCES}

[1]. S.M. Darwish*, S.D. Al-Dekhial, "Statistical Models For Spot Welding Of Commercial Aluminium Sheets", International Journal of Machine Tools \& Manufacture 39 (1999)1589-1610.

[2]. V.X. Trana, J. Pana,, T. Panb, "Effects of Processing Time on Strengths and Failure Modes of Dissimilar Spot Friction Welds Between Aluminum 5754-O and 7075-T6 Sheets" J materials processing technology 209(2009)3724-3739.

3]. Luo Yi a,b, Liu Jinhe, Xu Huibin, Xiong Chengzhi, Liu Lin , "Regression Modeling AndProcess Analysis Of Resistance Spot Welding On Galvanized Steel Sheet".Materials and Design 30 (2009) 2547-2555

[4]. A.G Thakur and V.M Nandedakar, "Application of Taguchi Method to Determine Resistance Spot Welding Conditions. of Austenitic Stainless Steel AISI304",Journal of scientific research Vol No.69,Septmber 2010 pp.680-683.

[5]. G. Mukhopadhyay .S. Bhattacharya b, K.K. Ray a, "Effect of Pre-Strain on The Strength of Spot-Welds". Materials and Design 30 (2009) 2345-2354.

[6]. M. Vural , A. Akkus, B. Eryurek, "Effect of Welding Nugget Diameter on The Fatigue Strength of The Resistance Spot Welded Joints of Different Steel Sheets". J Materials Processing Technology 176 (2006) 127-132.

[7]. A.M. Pereira, J.M. Ferreira . A. Loureiro,J.D.M. Costa , P.J. Bártolo, "Effect of Process Parameters on The Strength of Resistance Spot Welds In 6082-T6 Aluminium Alloy". Materials and Design31(2010)2454-463

[8]. M. Pouranvari , S.M. Mousavizadeh , S.P.H. Marashi , M. Goodarzi , M. Ghorbani , "Influence of Fusion Zone Size And Failure Mode on Mechanical Performance of Dissimilar Resistance Spot Welds of AISI 1008 Low Carbon Steel And DP600 Advanced High Strength Steel'.J Materials and Design xxx (2010) $\mathrm{xxx}-\mathrm{xxx}$ 